\title{
Development of a Measure: Internet Behaviors Scale
}

\author{
Samira Ranaiey ${ }^{1}$, Mohammad Reza Taghavi ${ }^{2} \&$ Mohammad Ali Goodarzi ${ }^{3}$ \\ ${ }^{1}$ Department Of Clinical Psychology, Shiraz, Iran \\ ${ }^{2}$ Department Of Clinical Psychology, Shiraz University, Shiraz, Iran \\ ${ }^{3}$ Department of Clinical Psychology,Shiraz University,Shiraz, Iran \\ Correspondence: Samira Ranaiey, Department of Clinical Psychology, Shiraz, Iran. E-mail: \\ Samira_ranaie@yahoo.com/Mtaghavi@rose.shirazu.ac.ir/mgoodarzi@rose.shiraz.au.ir \\ Received: February 27, 2016 \\ doi:10.5539/mas.v10n7p124 \\ Accepted: March 8, 2016 \\ Online Published: May 3, 2016 \\ URL: http://dx.doi.org/10.5539/mas.v10n7p124
}

\begin{abstract}
Background and aims: Previous studies had documented that Social Networking Sites (S.N.S) has pathological effect on its users. A multi dimension syndrome, called problematic Internet use (PIU), causing behavioral and cognitive symptoms, which results in negative impact on different aspects of life like social, professional or academic.

Because of increased attention to PIU, some measure had been made, but they seem to be inadequate, due to new issue of the internet interactions. Therefore the necessity and importance of standard, valid and reliable tools to assess PIU and the related behaviors is clear.

In a survey conducted by Morahan-Martin and Schumacher on differences between lonely and non-lonely in internet behaviors, "Internet Behaviors scale" was used.

The paper was frequently cited as a source by different researchers, but no validity or reliability for that scale was reported. The scale evaluates the different aspects of internet behavior which seems to be a quite helpful tool for PIU assessment.

Method: This survey presented results of a study that evaluate reliability and validity of "Internet Behaviors Scales" with Iranian university students. This questionnaire was completed by 156 volunteer students of Shiraz University. To assess reliability coefficient $\alpha$ and test retest method was conducted. To assess validity exploratory factor analysis and convergent and discriminant validity was conducted.

Results: Factor Analysis indicated three dimensions of this scale: social aspects, negative impact and competency and convenience aspect.

"The internet Behaviors Scale" as the results indicate showed acceptable reliability and validity with Iranian students.

Discussion: The internet Behaviors Scale as the results indicated could be used as a standard scale (valid and reliable) to evaluate PIU and related behaviors. It is important that validity and reliability of this scale be measured by other means.
\end{abstract}

Keywords: social networking sites, internet behaviors scale, validity, reliability, problematic internet use

\section{Introduction}

Research had documented that social Networking Sites (S.N.S) has pathological effect on its users. A multi dimension syndrome, called problematic Internet use (PIU), causing behavioral and cognitive symptoms, which results in negative impact on different aspects of life like social, professional or academic.

(Davis 2001; Morahan-Martia, Schumacher, 2003; Caplan 2002; Caplan, 2003)

Because of increased attention to PIU some measure had been made. But they seem to be inadequate, due to new issue of the internet interaction, so there is a necessary for efficient tools for psychological problem in the on-line interactions.

In a survey conducted by Morahan-Martin and Schumacher in 2003 on differences between lonely and non-lonely in internet behaviors, "Internet Behaviors scale" was used. 
The paper was frequently cited as a source by different researchers (including the Author), but no validity or reliability for that scale was reported. In this study we evaluate reliability and validity of this scale and by factor analysis we will see if the suggested three aspects of this scale explain total variance acceptably. (This scale was also used in survey that conducted by Author, titled as: "The Effect of loneliness on social Networking sites and its related behaviors". The article was submitted to Global Journal of Health science and the submission was accepted).

\section{Literature Review and Purpose}

As mentioned before, efficient, valid and reliable tools for assessment of PIU increasingly needed. Preference for online social Interaction (Leung, 2011) was measured by using 13 items based on Caplan $(2002,2003)$ studies, on the preference for on-line social interaction. 5 point Likert type scale was used, $1=$ strongly disagree and $5=$ strongly agree. Sample items included "Treated better online than in face to face relationship", "feel safer relating to others on-line", "more confident socializing on-line than offline", "more comfortable with computers than people", "I am willing to give up some of my face to face relationship", "to have more time for my online relationship" and "I am happier being on-line than I am off-line". Reliability was as high as 0.83 .

Another tool which was used in a study conducted by Caplan (2007), is Negative items used to operationalize negative out come associated with one's internet use, which were drown from measure employed in previous studies (Caplan 2002; Caplan 2005; Morahan - Martin - Schumacher 2003). Participants extend their agreement with three statements indicating that they had experienced negative outcome due to their internet use.

In that study reliability coefficient for negative out come reported $\alpha=0.70$.

To assess Facebook Group use and Gratifications, respondent were given a list of 16 statements, regarding Facebook group use (Park et al., 2009). They rated their level of agreement with specific reasons for using Facebook groups, including: information, acquisition about campus community, entertainment/recreation, and social interaction with friends and family, and peer pressure/self-satisfaction (1 strongly agree 6 strongly disagree). The statement were adapted from cluster of categorized dimension, describing on-line group participants (Lin hf, 2006; Rinding, Geten, 2004)

Addictive tendencies scale (Wilson et al 2010) based on previous research (Walsh et al 2007; Ehrenberg et al, 2008). The addictive tendencies scale $(\alpha=0.76)$ Compromised three items measuring level of salience: one of first thing I do each morning is log on to a social networking internet sites S.N.S (e.g. My space or Facebook) loss of control: (I find it hard to control use of S.N.S (e.g. My space or Facebook) and withdrawal: I feel lost when I cannot aces S.N.S (e.g. My space or Facebook)

The measure mentioned above, were some examples of tool which are recently used for PIU evaluation.

This study attends to evaluate validity and reliability of "Internet Behaviors Scale" with Iranian students and also and also using factor analysis to see if three suggested aspects of this scale explain total variance acceptably.

\section{Method}

\subsection{Participants}

"Internet Behaviors scale" was given to 156 shiraz university students. Of these $146(93.6 \%$ has experienced S.N.S use and were included in the research. $108(69.2 \%)$ were female and $42(26.9 \%)$ were male. The sample included 11 (7.1\%) freshmen 34 (21.8\%) Sophomore, 30 (19.2\%) Juniors, 6 (3.8\%) seniors. 41 (26.3\%) graduate student and 31 (19.9\%) PHD students participants had reported average weekly use as 18.01 hours ( $\mathrm{SD}=20.38)$. as mentioned earlier this scale was used by Morahan-Martin and Schumacher (2003) but no validity or reliability for this scale was reported.

\subsection{Measures}

The questionnaire completed by the Participants, including demographic characteristic, S.N.S experience and Internet Behaviors scale. (Those who had S.N.S use experience included in the survey)

\subsection{Procedure}

Internet behaviors were assessed by 38 Likert - type questions, the three aspects are: social aspects of S.N.S use (19 questions), negative impact of S.N.S use (15 questions) and feeding of competency online (4 questions). A four point scale was used. With 1 strongly disagree and 4 strongly agree. In this survey the mean \pm SD for social aspect was $36.46 \pm 9.58$. for negative impact $29 \pm 9.30$ and for competency online $11.06 \pm 2.09$.

\subsection{Statistical Analysis}

For evaluating reliability coefficient $\alpha$ and test-retest were conducted, for evaluating validity, exploratory factor 
analysis and also convergent validity and discernment validity were conducted.

\subsection{Ethics}

Ethical approval: All procedures performed in studies involving human participants were in accordance with ethical standards of institutional and national research committee with the 1964 Helsinki declaration and its later amendments or comparable ethical standards.

Informed consent: Informed consent was obtained from all individual participants included in this study.

\section{Results}

\subsection{Reliability}

3.1.1 Coefficient $\alpha$ Reliability was as heigh as $\alpha=0.89$ for social aspect, $\alpha=0.94$, for negative impact and $\alpha=0.66$ for convenience and competency aspect with Iranian students.

\subsubsection{Test - Retest Method}

The scale of Internet Behaviors was given to 30 Shiraz university students and after 3 weeks the same test was conducted. Table 3-1 provides the descriptive statistics (Mean \pm SD) for subscales scores. We used correlated samples t-test to formally test whether means are similar.

A Pearson's correlation is computed to assess test-retest reliability. Note means are similar, and this table indicates that the correlation of the two scores (per subscale) is high and positive so there is strong support for the test-retest reliability. See table 3-1 after the references.

\subsection{Validity}

3.2.1 Exploratory Factor Analysis (Principal Component Method with Varimax Rotation) Was Conducted.

The results indicated three dimension (Social aspect, negative impact and competency and convenience online). This three dimension explain $48.18 \%$ of the total variation of the scale result Presented in table 3-2. See table 3-2 after the references.

According to the second table (3-2) almost all the items are located in their dimensions. Expect these that marked in red color. With a little neglect they could be located in their dimensions. The only item which is not in appropriate dimension is No. 18 of social aspect, which has a preference to locate in competency and convenience aspect. This could be due to the characteristics of our sample or the item probably should be in the third dimension.

\subsubsection{Convergent Validity and Discriminant Validity}

To evaluate validity of Internal Behaviors scales convergent and discriminate validity was assessed. See table 3-4 after the references.

These finding show that scaling success rate for convergent validity is $100 \%$ for all domains expect for social

aspect which is $89.4 \%$. The success rate for item discriminant validity of internet Behaviors scale is 96.05 ( $\overline{76}$ ) (this statistical Method for convergent and discernment validity is based on Fayers, 2000). As the result show overall validity is acceptable for internet Behaviors scale.

\section{Discussion}

"The internet Behaviors Scale" as the results indicate showed acceptable reliability and validity with Iranian students. The results of exploratory factor analysis indicated three aspects, social aspect, negative impact and competency and convenience aspect, explain total variation acceptably.

\section{Conclusion}

A number of scholars have noted the need for standard scales to assess internet behaviors along with more empirical evidence. The scale of Internet Behaviors could be a helpful device to evaluate PIU and its related behaviors. It is important that validity and reliability of this scale be measured by other means. It is also suggested that the scale, being evaluated on more diverse population.

\section{References}

Amiel, T., \& Sargent, S. L. (2004) Individual difference in Internet usage motives. Computers in Human Behavior, 20, 711-26. 
Caplan, S. E. (2002). Problematic Internet use and Psychological well-being development of a theory based cognitive-behavioral measure. Computers in Human Behavior, 18, 533-575.

Caplan, S. E. (2003). Preference for online social interaction: a theory of problematic Internet use and psychological we-being. Communication Research, 30, 625-648.

Coplan, S. E. (2007). Relation among Loneliness, social Anxiety and Problematic Internet Use. Cyber Psychology \& Behavior.

Davis, R. A. Flett, G. L., \& Besser, A. (2002). Validation of a new measure of problematic Internet use: Implications for pre-employment screening. CyberPsychology \& Behavior, 5, 331-346.

Davis, R.A. (2001). A cognitive-behavioral model of pathological Internet use. Journal of Communication, 17 , 187-195.

Ehrenberg, A. Juckes, S., White, K. M., \& Walsh, S. P. (2008). Personality and self-esteem as predictors of young peoples technology use. CyberPsychology \& Behavior, 11, 739-41.

Fayers, P. M., \& Machin, D. (2000). Assessment Analysis an Interpretation. Quality of life, pp 50-70.

Hamburger, Y. A., \& Ben-Artzi, E. (2000). The relationship between extraversion and neuroticism and the different uses of the Internet. Computers in Human Behavior, 16, 441-49.

Hardie, E., \& Tee, M. (2003). Excessive Internet use: The role of personality, loneliness and social support networks in Internet addiction. Australian Journal of Emerging Technology and Society, 5, 34-47.

Lennug, L. (2011). Loneliness, social support and preference for online social interaction: The mediating effect of identity experimentation online among children and adolescence. Chinese Journal of Communication, 4, 381-399.

Lin, H. F. (2006). Understanding behavioral intention to participate in virtual communities. Cyber Psychology \& Behavior, 9, 540-7

McEllroy, J. C. Hendrickson, A. R. Townsend, A. M., \& Demarie, S. M. (2007). Dispositional factors in internet use: Personality versus cognitive style. MIS Quarterly, 31, 809-20.

Morahan-Martin, J., \& Schumacher, P. (2003). Loneliness and social uses of the Internet. Computers in Human Behavior, 19, 659-671.

Pack, N., Kee, K. F., \& Valen Zuela, M. A. (2009). Being immersed in social Networking Environment: Facebook groups, Uses and Gratifications and social outcome. Cyber Psychology \& Behavior, 12.

Ridings, C. M., \& Geten, D. G. (2007). Virtual community attraction: why people hang out online. Journal of Computer Mediated Communication, 2004(10). Retrieved from http://jcmc.indiana.edu/vol10/issue1/ridings-geten

Walsh, S. P., White, K. M., \& Young, R. M. (2007). Young and connected: Psychological influences of mobile phone use amongst Australian youth. In: Goggin G, Hjorth L, and eds. Mobile Media 2007: Proceeding of an international conference on social and cultural aspects of mobile phones, media and wireless technologies, Sydney: University of Sydney, pp. 125-34.

Wilson, K., Fomasier, S., \& White, K. M. (2010). Psychological Predictors of young adults: use of social networking sites. Cyberpshychology, Behavior, and Social Networking, 13(2), 173-177.

\section{Tables}

Table 3-1. Results of test - retest

\begin{tabular}{|c|c|c|c|c|c|}
\hline Dimensions & First time & $\begin{array}{l}\text { Second } \\
\text { time }\end{array}$ & $\begin{array}{l}\text { The difference between first } \\
\text { and second time }\end{array}$ & $\begin{array}{l} \\
\text { value }\end{array}$ & $\begin{array}{l}\text { Correlation } \\
\text { value }\end{array}$ \\
\hline Social aspect & $33.48 \pm 9.11$ & $33.81 \pm 9.17$ & $-.31 \pm 1.78$ & .378 & $.981(.000)$ \\
\hline Negative impact & $26.48 \pm 9.57$ & $26.67 \pm 9.16$ & $-.19 \pm 1.8$ & .597 & $.983(.000)$ \\
\hline $\begin{array}{l}\text { Competency and } \\
\text { convince }\end{array}$ & $10.78 \pm 1.94$ & $10.74 \pm 1.77$ & $.04 \pm .98$ & .846 & $.865(.000)$ \\
\hline
\end{tabular}


Table 3-2. Results of exploratory factor analysis for internet Behaviors scale

\begin{tabular}{|c|c|c|c|c|c|c|c|c|c|}
\hline \multicolumn{10}{|c|}{ Total Variance Explained } \\
\hline \multirow[t]{3}{*}{ Component } & \multicolumn{3}{|c|}{ Initial Eigenvalues } & \multicolumn{3}{|c|}{ Extraction Sums of Squared Loadings } & \multicolumn{3}{|c|}{ Rotation Sums of Squared Loadings } \\
\hline & Total & $\% \quad$ of & Cumulative $\%$ & Total & $\% \quad$ of & Cumulative \% & Total & $\% \quad$ of & Cumulative $\%$ \\
\hline & & Variance & & & Variance & & & Variance & \\
\hline 1 & 13.761 & 36.214 & 36.214 & 13.761 & 36.214 & 36.214 & 7.879 & 20.735 & 20.735 \\
\hline 2 & 2.362 & 6.216 & 42.429 & 2.362 & 6.216 & 42.429 & 7.863 & 20.691 & 41.426 \\
\hline 3 & 2.184 & 5.748 & 48.178 & 2.184 & 5.748 & 48.178 & 2.566 & 6.751 & 48.178 \\
\hline 4 & 1.795 & 4.724 & 52.901 & & & & & & \\
\hline 5 & 1.518 & 3.996 & 56.897 & & & & & & \\
\hline 6 & 1.309 & 3.445 & 60.342 & & & & & & \\
\hline 7 & 1.197 & 3.149 & 63.491 & & & & & & \\
\hline 8 & 1.127 & 2.967 & 66.458 & & & & & & \\
\hline 9 & 1.008 & 2.652 & 69.110 & & & & & & \\
\hline 10 & .935 & 2.460 & 71.570 & & & & & & \\
\hline 11 & .872 & 2.294 & 73.863 & & & & & & \\
\hline 12 & .771 & 2.029 & 75.893 & & & & & & \\
\hline 13 & .728 & 1.915 & 77.808 & & & & & & \\
\hline 14 & .696 & 1.832 & 79.640 & & & & & & \\
\hline 15 & .607 & 1.598 & 81.238 & & & & & & \\
\hline 16 & .597 & 1.571 & 82.809 & & & & & & \\
\hline 17 & .552 & 1.453 & 84.262 & & & & & & \\
\hline 18 & .548 & 1.443 & 85.706 & & & & & & \\
\hline 19 & .500 & 1.317 & 87.023 & & & & & & \\
\hline 20 & .475 & 1.251 & 88.273 & & & & & & \\
\hline 21 & .424 & 1.116 & 89.389 & & & & & & \\
\hline 22 & .419 & 1.102 & 90.491 & & & & & & \\
\hline 23 & .395 & 1.040 & 91.531 & & & & & & \\
\hline 24 & .361 & .949 & 92.481 & & & & & & \\
\hline 25 & .309 & .814 & 93.294 & & & & & & \\
\hline 26 & .292 & .769 & 94.063 & & & & & & \\
\hline 27 & .285 & .749 & 94.812 & & & & & & \\
\hline 28 & .259 & .682 & 95.494 & & & & & & \\
\hline 29 & .245 & .646 & 96.139 & & & & & & \\
\hline 30 & .237 & .624 & 96.764 & & & & & & \\
\hline 31 & .217 & .571 & 97.335 & & & & & & \\
\hline 32 & .184 & .483 & 97.818 & & & & & & \\
\hline 33 & .174 & .457 & 98.275 & & & & & & \\
\hline 34 & .173 & .455 & 98.729 & & & & & & \\
\hline 35 & .155 & .407 & 99.136 & & & & & & \\
\hline 36 & .120 & .316 & 99.453 & & & & & & \\
\hline 37 & .108 & .285 & 99.737 & & & & & & \\
\hline 38 & .100 & .263 & 100.000 & & & & & & \\
\hline
\end{tabular}

Table 3-3. Rotated component matrix

\begin{tabular}{llll}
\hline \multicolumn{4}{c}{ Rotated Component Matrix } \\
\cline { 2 - 4 } & \multicolumn{3}{c}{ Component } \\
& 1 & 2 & 3 \\
c1 & .638 & .278 & .203 \\
c2 & .676 & .310 & .073 \\
c3 & .672 & .358 & .255 \\
c4 & .569 & .445 & .061
\end{tabular}




\begin{tabular}{llll}
$\mathrm{c} 5$ & .651 & .406 & .023 \\
$\mathrm{c} 6$ & .611 & .413 & .174 \\
$\mathrm{c} 7$ & .605 & .284 & .133 \\
$\mathrm{c} 8$ & .704 & .216 & -.169 \\
$\mathrm{c} 9$ & .662 & .273 & .032 \\
$\mathrm{c} 10$ & .613 & .416 & .250 \\
$\mathrm{c} 11$ & .712 & .381 & .057 \\
$\mathrm{c} 12$ & .441 & .457 & .226 \\
$\mathrm{c} 13$ & .685 & .221 & -.314 \\
$\mathrm{c} 14$ & .343 & .040 & .374 \\
$\mathrm{c} 15$ & .268 & -.171 & -.194 \\
$\mathrm{c} 16$ & .614 & .284 & .012 \\
$\mathrm{c} 17$ & .648 & .269 & -.283 \\
$\mathrm{c} 18$ & .338 & .132 & .460 \\
$\mathrm{c} 19$ & -.505 & -.043 & -.090 \\
$\mathrm{~d} 1$ & .139 & .529 & -.113 \\
$\mathrm{~d} 2$ & .192 & .731 & .025 \\
$\mathrm{~d} 3$ & .270 & .715 & -.007 \\
$\mathrm{~d} 4$ & .387 & .566 & .097 \\
$\mathrm{~d} 5$ & .272 & .627 & .070 \\
$\mathrm{~d} 6$ & .078 & .418 & -.256 \\
$\mathrm{~d} 7$ & .300 & .715 & -.073 \\
$\mathrm{~d} 8$ & .224 & .784 & .168 \\
$\mathrm{~d} 9$ & .419 & .480 & .413 \\
$\mathrm{~d} 10$ & .267 & .569 & .301 \\
$\mathrm{~d} 11$ & .171 & .642 & .237 \\
$\mathrm{~d} 12$ & .304 & .600 & .139 \\
$\mathrm{~d} 13$ & .432 & .553 & .270 \\
$\mathrm{~d} 14$ & .272 & .683 & .001 \\
$\mathrm{~d} 15$ & .238 & .710 & -.083 \\
$\mathrm{e} 1$ & -.152 & -.181 & .144 \\
$\mathrm{e} 2$ & -.094 & -.232 & .702 \\
$\mathrm{e} 3$ & .144 & .041 & .767 \\
$\mathrm{e} 4$ & -.072 & .120 & .185 \\
\hline & & & \\
\hline
\end{tabular}

Extraction Method: Principal Component Analysis. Rotation Method: Varimax with Kaiser Normalization a. Rotation converged in 5 iterations

Table 3-4. Convergent Validity and Discriminant validity of the scale of internet behaviors

\begin{tabular}{|c|c|c|c|c|c|c|c|}
\hline & & Discriminant valid & ity $^{\mathrm{b}}$ & & Convergent validit & & \\
\hline Dimensions & Items & $\begin{array}{l}\text { Range } \\
\text { correlation }\end{array}$ & $\begin{array}{l}\text { Scaling } \\
\text { (percent) }\end{array}$ & success & $\begin{array}{l}\text { Range } \\
\text { correlation }\end{array}$ & $\begin{array}{l}\text { Scaling } \\
\text { (percent) }\end{array}$ & success \\
\hline
\end{tabular}




\begin{tabular}{|c|c|c|c|c|c|}
\hline Social aspect & 19 & $0.003-0.745$ & $(100)^{38 / 38}$ & $0.011-0.791$ & $(89.4)^{17 / 19}$ \\
\hline Negative impact & 15 & $0.011-0.139$ & $(93.3)^{28} / 30$ & $0.616-0.843$ & (100) ${ }^{15} / 15$ \\
\hline $\begin{array}{l}\text { Competency and } \\
\text { convince }\end{array}$ & 4 & $0.019-0.819$ & & $0.472-0.845$ & (100) $4 / 4$ \\
\hline
\end{tabular}

\section{Appendix I}

\section{Scale of Internet Behaviors (Social Aspect)}

1 - My online friends understand me better than other people.

2- I am more myself online that in real life.

3- I open up more to people online than in other communications modes.

4- Most of my friends I know from online.

5 - I prefer communication online to face to face communication.

6- I am friendlier online than in real life.

7- The anonymity of being online is liberating.

8- I have shared intimate secrets online.

9- I have lurked online but never entered a conversation online.

10- Going online has made it easier for me to make friends.

11- I have more fun with the people I know online than others.

12- I have a network of friends made online.

13- Sometime I pretend I am someone I am not while online.

14- I like the speed of communication online.

15- I prefer telephoning to communicating online. (reverse)

16- Online communication lets me control when I want to communicate.

17- I have pretended to be somebody of the opposite sex while online.

18- Being online has made it easier to communicate with people I know.

19- I feel less connected interpersonally when I communicate online. (reverse)

\section{Appendix II}

\section{Scale of Internet Behaviors (Negative Impact)}

1- I feel guilty about time spent online instead of at other require work.

2- I have been told that I spend too much time online.

3- I have routinely cut short on sleep to spend more time online.

4- I have gone online to make myself feel better when down or anxious.

5 - I have use online to talk to others when I was feeling isolated.

6- I have missed social engagements because of online activities.

7- I have missed classes or work because of online activity. 
8- I have attempted to spend less time online but have not being able to.

9- When I am online, I feel totally absorbed.

10- If it has been along times since I last logged on, I find it hard to stop thinking about what will be waiting for me when I do.

11- I have tried to hide from others how much time I am actually online.

12- I have gotten in to trouble with my employer or school because of being online.

13- I sometime go online to escape from pressure.

14- I have never gotten in to an argument with a significant other over being online.

15- My work and / or school performance has not deteriorated since I started going online.

\section{Appendix III}

\section{Scale of Internet Behaviors (Competency and Convenience Aspect)}

1 - I avoid going online for information because there is too much to weed through. (reverse)

2- I feel competent in my ability to use online services.

3- I am comfortable using online services.

4- Going online has made it easier for me to do research.

\section{Copyrights}

Copyright for this article is retained by the author(s), with first publication rights granted to the journal.

This is an open-access article distributed under the terms and conditions of the Creative Commons Attribution license (http://creativecommons.org/licenses/by/3.0/). 